\title{
Multiple Dimensions of Biological Development: Implications for Kindergarten Readiness Among Young Children in Poverty
}

\author{
Dominic F. Gullo \\ Early Childhood Education, School of Education \\ Drexel University, Philadelphia, Pennsylvania, USA
}

Received: July 20, 2014 Accepted: September 27, $2014 \quad$ Published: October 1, 2014

doi:10.5296/jsss.v2i1.6394 URL: http://dx.doi.org/10.5296/jsss.v2i1.6394

\begin{abstract}
The purpose of this study was to examine differences in low-socioeconomic (SES) children's kindergarten readiness reflecting multiple dimensions of their biological development. Independent variables included birth-weight, health status, gender, and kindergarten entry age. Dependent variables included measures of academic achievement, psychomotor development, as well as parents' and teachers' ratings of social competence. A low-SES sample of 3,301 boys and 3,208 girls who were enrolled in kindergarten for the first time were drawn from the United States Department of Education Early Childhood Longitudinal Study - class of 1998 1999 Kindergarten Cohort data set. Multivariate analyses of variance were performed on the readiness variables to determine differences in performance among children with different biological factors. Results indicated that there were differences among children depending on certain aspects of their biological characteristics, thus indicating that children who reside in poverty are not a homogeneous group who should be viewed and taught as though they were homogeneous in their characteristics. Implications for teaching and future research are suggested.
\end{abstract}

Keywords: Social class, Kindergarten, School readiness, Achievement, Social competence 


\section{Introduction}

Kindergarten readiness is a term often used when referring to the degree to which children are prepared for a formal school experience. As such, "kindergarten readiness" is often interchangeable with "school readiness." "Early school readiness has emerged as an issue in the forefront of international research and policy" (Romano, Babchishin, Pagani, \& Kagan, 2010, p. 995). While early school readiness is associated with children's level of proficiency in academic performance, particularly in literacy and mathematics, it is concurrently believed that early school readiness is not limited to proficiency in these areas alone. Rather, school readiness is reflected in a constellation of skills and behaviors related to intellectual, physical, and social competence (Card, 1999; Duncan et. al., 2007; Heckman, 2006; Romano et al., 2010).

In another area of research on school readiness, researchers have investigated the relationship between dimensions of readiness and later school achievement (Classens, Duncan, \& Engel, 2009; Hair, Halle, Terry-Humen, Lavelle, \& Calkins, 2006; Li-Grining, Votruba-Drzal, Maldonado-Carreño, \& Haas, 2010; Romano et al., 2010). In these studies, children who enter kindergarten with a particular set of academic and social skills are more likely to be academically and economically successful in the future as compared to children who lack these attributes.

A well-established facilitatingfactor affecting school readiness is socioeconomic status (SES). Low-SES children enter kindergarten lagging behind in the academic and social proficiency skills necessary to do well in school when compared to their more advantaged peers (Ayoub et al., 2009; Lee \& Burkam, 2002; Ready, 2010). These differences become exacerbated as these children progress through school (Downey, von Hippel, \& Beckett, 2004; Reardon, 2003). In most previous investigations, researchers often looked for social class differences in children's academic readiness therefore using SES as an independent variable (e.g., Isaacs, 2012). That is, in these studies investigators looked for differences among the various SES groups (low, middle or high). In making such comparisons among SES groups, there is an inherent assumption that there is pervasive homogeneity within SES groups. While there are a number of risk factors associated with being low-SES, studies have indicated that protective factors can ameliorate some of the negative impact of poverty on certain outcomes for children, resulting in resiliency (Ayoub et al., 2009; Fedor, Bender, \& Carlson, 2010). Thus, it has been found that poverty does not affect all children equally.

The purpose of the present study was to examine differences in low-SES children's kindergarten readiness as it is reflected in multiple dimensions of their biological development. Specifically, this research investigated how low-SES children's birth-weight, health status, gender, and kindergarten entry age differentially affected school readiness as they prepared to enter kindergarten. While it may be argued that these biological factors are largely immutable, knowing how differential gradations of these factors affect low-SES children's readiness for formal schooling may be informative and lead to policies and practices that are designed to offset the potential negative impact of these factors on school readiness and be of benefit to children who reside in economic poverty. 


\section{School Readiness}

The effects of school readiness reach far beyond the first few months of kindergarten. It has been found that children at age five with higher levels of school readiness are generally more successful in grade school and are less likely to drop out of high school. This is true even after adjusting for family background (Duncan et al., 2007; Duncan, Morris, \& Rodrigues, 2011).

The concept and definition of school readiness varies depending on the context in which it is being used. In one context, school readiness refers to the developmental traits that determine whether or not a child is ready to enter kindergarten. If it is determined that they are not ready for kindergarten the parents of these children are advised to wait a year before sending their child to school (Uphoff \& Gilmore, 1985; Winsler et al., 2012). In another context, children are ready for kindergarten if they meet certain age requirements and consequently, the teacher will develop the appropriate curriculum and teaching strategies to meet their individual needs (Cross \& Conn-Powers, 2011).

"In theory, a definition of school readiness should identify the foundational skills, content knowledge, and concepts that children need when they enter school in order to achieve academic success in early elementary school and beyond" (National Center for Children in Poverty \& Abt Associates Inc., 2008, p. 6). Therefore, readiness implies that children must become proficient in being able to appropriately manage certain skills and abilities in order to effectively function both academically and socially in a school setting (Hair et al., 2006). School readiness includes a broad set of characteristics and skills that affect the child's ability to learn in academic environments, including such things as physical health and well-being, motor skills, behavioral and emotional self-regulation, social and communication skills, pre-academic skills, attention, curiosity and motivation to learn (Pianta \& Cox, 1999). However, according to Meisels (1999), readiness is relative; "one child's readiness may be another child's long-ago accomplishment or another child's yet-to-be-achieved success ( $\mathrm{p}$. 44). Because development is so highly variable at the kindergarten age, a major concern is developing a single standard of what it means to be "ready for school." Identifying a single indicator of readiness and measuring it also poses a significant problem (Gullo \& Hughes, 2011; Hughes \& Gullo, 2010).

Despite the underlying difficulties related to defining school readiness, there is agreement in the field that school readiness is a multidimensional concept. There is also agreement that school readiness is dependent upon those characteristics and qualities that the child brings to the learning experience as well as being dependent on the context in which learning occurs. These contexts include home, school, as well as broader community settings (Hair et al., 2006). A view of school readiness has emerged that is more comprehensive and reflects the interaction that takes place among those inherent characteristics that the child brings to the situation along with past and present cultural and environmental contexts (Carlton \&Winsler, 1999; May \& Kundert, 1997). The structure for the multi-dimensional definition school readiness has been articulated by the National Educational Goals Panel (NEGP: Kagan, Moore, \& Bredekamp, 1995). Three components of school readiness were identified:

1. The child's readiness for school reflected in his or her ability to participate in academic experiences and learn from them; 
2. The school's readiness to receive children reflected in their ability to provide meaningful and relevant learning experiences; and

3. Family supports and community services that ultimately contribute to the child's school readiness.

The present study will focus on how the first component (the child's readiness for school) is affected by biological characteristics of the child. According to the NEGP, there are five dimensions associated with the child's readiness for school. It should be noted that each of these dimensions is important and necessary for school readiness, but not sufficient in and of itself (Kagan et al., 1995).

The first dimension is physical health which encompasses physical well-being and motor development. Included in this dimension are rate of growth, physical fitness, fine and gross motor skills, and health status. Social/emotional development is the second dimension of school readiness. This includes such things as the ability to form positive relationships with peer and teachers as well as elements of self-concept and self-efficacy. In addition, this dimension includes the ability to express one's feelings in an appropriate manner and being sensitive to the feelings of others. The third dimension of school readiness is approaches to learning. Approaches to learning includes being open to and curious about tasks and challenges, being persistent, flexible, imaginative, and attentive. Research has found that children's early approaches to learning enhance their ability to adapt to the demands they experience with the start of formal schooling (Li-Grining et al., 2010) such as completing work independently, adhering to strict time schedules, and acquiring basic skills. Language development is the fourth dimension of school readiness. This includes both verbal language and emergent literacy. Verbal language is reflected in children's ability to listen, use language effectively and in being able to effectively manage the social conventions of language. Emergent literacy skills are the prerequisite competencies that are necessary for reading and writing development. These include such things as showing interest in books and stories, print awareness, and emergent writing. The final dimension of school readiness is cognitive development and general knowledge. These are expressed in the child's knowledge of concepts and properties of objects as well as acquiring the conventions of school-learned knowledge (Kagan et al., 1995).

\section{Poverty and School Readiness}

The effects of poverty on children's development and academic performance are well documented in the literature (Engle \& Black, 2008). Studies show that low-SES children score lower on math and reading assessments, on behavioral assessments, and on measures of health status when compared to higher SES counterparts (Isaacs, 2012). The negative effects of poverty can be seen as early as the second year of life and extend through elementary and into high school (Entwisle, Alexander, \& Olsen, 2005). When the risk factors associated with poverty are present during preschool, they affect kindergarten readiness which has been shown to set the trajectory for future school performance and success (Zigler, Gilliam, \& Jones, 2006). "School readiness has been shown to be predictive of virtually every education benchmark (e.g., achievement test scores, grade retention, special education placement, dropout, etc)" (p. 21). As has been stated previously, children who come from low-SES backgrounds start school at a disadvantage (Isaacs, 2012). It has been found that children who 
start kindergarten significantly behind their age-mates academically and developmentally can almost never close the readiness gap, but rather, the gap widens as they progress through their years in school (Lee \& Burkam, 2002).

Nearly two out of three children who are born into the bottom fifth of the income distribution remain in the bottom two-fifths of the distribution as they reach adulthood (Isaacs, Sawhill, \& Haskins, 2009). It has also been found, however, that low-SES children who enter kindergarten at higher levels of readiness than their classmates have an increased chance of reaching middle-class status by age 40 (Winship, Sawhill, \& Gold, 2011). Thus, poverty and lack of school readiness are not necessarily correlated. That is, not all children who come from homes of economic poverty can be labeled as lacking school readiness knowledge and skills.

The negative effects of poverty on school readiness can be associated with factors related to multiple sources of influence. There are primarily two different views as to why low-SES children have lower outcomes when compared to higher SES children (Isaacs, 2012). Economic differences and family life circumstances are the two most cited reasons. Together or singly these two factors may lead to differential influences on child development, heath status, and experiential opportunities. As previously stated, while much is known about how certain factors affect children's development, learning and behavior across different SES groups, few studies have investigated how differences in readiness factors affect children within a low-SES group of kindergarten aged children. In this investigation, the focus was on characteristics related to children's biological development and maturational status and the ways in which these differentially affected dimensions of school readiness among a group of low-SES kindergarten children.

\section{School Readiness and Biological Influences}

There are a number of biological influences related to behavioral outcomes that have come to be associated with a child's school readiness risk factors. One biological influence is the child's gender. This factor is of particular importance as the child enters school for the first time. Generally speaking, evidence suggests that girls outperform boys on measures of academic achievement associated with kindergarten readiness (Isaacs, 2012; Janus \& Duku, 2007). This is particularly true among children in lower SES groups. Isaacs (2012) found that girls were 16 percentage points higher than boys on average and this gender gap remains constant even when statistical controls for family background are applied. Further, it was found that being male, coupled with suboptimal health and coming from a home of economic poverty, contribute most strongly to broad levels of vulnerability at school entry (Janus \& Duku, 2012).

The chronological age at which children enter kindergarten has also been a focus of study relative to its effects on measures of kindergarten readiness (Crosser, 1991; Gullo \& Burton, 1992; Janus et al., 2007; NICHD, 2007; Spitzer, Cupp, \& Parke, 1995; Stipek, 2002). In general, children who enter kindergarten at younger ages score lower on measures of academic achievement associated with kindergarten readiness as compared to children who are chronologically older. In some studies these differences were maintained into the third grade (NICHD, 2007) and sixth grade (Crosser, 1991). Uphoff and Gilmore (1985), who were early proponents of postponing kindergarten for young age eligible children, suggested that 
children should enter kindergarten based on their developmental age and not their chronological age. They suggested that if children enter kindergarten earlier than 5 years, 6 months, they should be considered young for their class; further, they suggest that in this situation, age becomes a risk factor for children's not succeeding in school either academically or socially.

Low birth weight has also been found to be negatively associated with children's kindergarten readiness (Isaacs, 2012). Children born under 2500 grams or 5.5 pounds are considered to be low birth weight. Deleterious effects are compounded if the child is low-SES. Low birth weight is associated with lower academic performance, higher incidence of school identified disabilities, and behavioral problems associated with inattentive, aggressive and hyperactive behaviors (Anderson \& Doyle, 2003; Bhutta, 2002; Nonkin, Scott, $\&$ Mason, 2001). The consequences of low birth weight affect both kindergarten readiness as well as long-range academic and behavioral performance.

Finally, the health status of the child can have an effect on his or her readiness for school (Janus \& Duku, 2007). The child's health status can affect academic performance in many ways. The effects of being medicated can have a negative impact on both academic and social competence (Naude \& Pretorius, 2003). Children that miss school often due to chronic illness have lower school attendance and therefore have less opportunity to participate in school activities. Chronic health problems may also lead to behavioral difficulties in children (Barlow \& Ellard, 2006).

\section{The Present Study}

As stated previously, the majority of the research examining the effects of poverty on children's academic readiness has primarily focused on the comparison of children who come from low-SES homes and communities with children who come from middle- and upper-SES backgrounds. In this study, differences among children from low-SES homes will be studied. Specifically, the following research question will be examined: What are the effects of children's biological characteristics (birth weight, gender, health rating, and kindergarten entry age) on low-SES children's school readiness factors related to cognitive development, psychomotor development and social competence?

\section{Method}

\subsection{Dataset}

The dataset that was used for this study came from the Early Childhood Longitudinal Study Kindergarten Cohort (ECLS-K), class of 1998 - 1999. The ECLS-K is a dataset collected from a large nationally representative sample of kindergarten children and sponsored by the National Center for Educational Statistics (NCES, 2000). Approximately 22,000 kindergarten children were followed from the fall of their kindergarten year through eighth grade. Data were collected in the fall and spring of the kindergarten year, fall and spring of first grade, spring of third, fifth and eighth grades. Asian and Pacific Islander children were oversampled by ECLS-K in order to insure that the sample size was large enough to permit analyses of the subgroups. Since the focus of this study is kindergarten readiness, data from the fall of the kindergarten year were used. Data on each child came from parent and teacher interview as well as from direct child assessments. The data collected on children from parents, teachers, 
and schools, as well as through direct child assessments, provide information on child development in cognitive, social-emotional as well as physical domains. In addition, demographic data as well as background characteristics information were collected on children, families, teachers and schools in order to capture a depiction of the bio-ecological context in which the child lives and develops.

\subsection{Sample}

The sample for this study was drawn from the full ECLS-K sample of first time kindergarteners $(\mathrm{N}=17,219)$. First time kindergartners were selected for this study in order to focus on school readiness in those children who are entering formal schooling for the first time. For this study, only data for children who were identified as being in the lower socioeconomic strata were analyzed. In the ECLS-K data, SES was computed as a composite variable. SES was computed at the individual household level and included the following components: father/male guardian's education; mother/female guardian's education; father/male guardian's occupation; mother/female guardian's occupation; and household income. Each of these indices was standardized so that the mean was " 0 " and the standard deviation was " 1 ." The children's parents reported both their education and occupation during the fall of the kindergarten year. Parent's education was coded as follows: $1=$ completed grade 8 or below; 2 = completed grades $9-12 ; 3=$ high school diploma or equivalent; $4=$ participation in a vocational or technical program; $5=$ some college; $6=$ bachelor's degree; 7 $=$ graduate or professional school without completing degree; $8=$ master's degree; $9=$ doctorate or professional degree. Occupational prestige was coded in accordance with guidelines provided by the General Social Survey (National Center for Educational Statistics, 2001). Both continuous and categorical SES composite variables were computed. In this study the categorical SES variable was used to select those children who belonged to the low-SES group. Quintiles were created to represent the value of the SES. Only children who were in the quintile representing the lowest SES group were included in the study.

The sample of Low-SES children used for this study included 3301 males (50.7\%) and 3208 females $(49.3 \%)$. The average age at which the children entered kindergarten was 65.67 months $(\mathrm{SD}=4.09)$. The sample was ethnically diverse and included $36.5 \%$ non-Hispanic White, $21.9 \%$ non-Hispanic Black, 30.1\% Hispanic, and $11.3 \%$ other. Additionally, $46.2 \%$ of the children resided in urban areas, $30.1 \%$ resided in suburban areas, and $23.8 \%$ resided in rural areas.

\subsection{Measures}

The measures used for this study came from ECLS-K direct child observations as well as parent and teacher interviews and child ratings (NCES, 2000). The dependent and independent variables chosen for this study derived from the theoretical and empirical context discussed in the review of literature. The dependent variables for this study were factors related to kindergarten readiness. The independent variables were biological factors cited as having potential influence on children's school readiness.

\subsubsection{School Readiness Factors}

School readiness factors included variables related to cognitive development (reading, mathematics, general knowledge achievement), psychomotor development (fine and gross 
motor), and social competence (approaches to learning and interpersonal skills).

The ECLS-K direct cognitive assessments contained items related to reading, mathematics and general knowledge. Each child received a 12 to 20 item routing assessment. Depending on the results of the routing assessment, one of several second stage forms were used that contained items of the appropriate difficulty for the level of ability that was indicated in the routing assessment. Reading, Mathematics, and General Knowledge Item Response Theory (IRT) scale scores were used for analysis. IRT scale scores makes it possible to compare scores regardless of which second stage assessment form children were administered. It is recommended to use IRT scale scores in order to identify differences among subgroups in achievement that correlates with demographic and status variables, such as those used in this investigation. The reading assessment was designed to measure basic language and reading skills, vocabulary, and comprehension. Mathematical assessment items were designed to measure conceptual knowledge skills, procedural knowledge and problem solving. The general knowledge assessment consisted of items related to science and social studies. The assessments were administered in the fall of the kindergarten year. For the reading IRT scale score, the range was $0-72$, the mean was 22.0 with a standard deviation of 8.3 . For math, the range was $0-64$, the mean was 19.1 with a standard deviation of 7.2. The general knowledge range was $0-51$, with a mean of 22.1 and a standard deviation of 7.4. Reliabilities for these scales ranged from 0.88 to 0.95 .

Psychomotor development was assessed individually and included two scales. Fine motor skills were assessed by measuring visual motor skills. This was predominately a measure of eye-hand coordination. Seven tasks were presented to children as a measure of eye-hand coordination (build a gate, draw a person, copy five simple figures). Gross motor skills were assessed by measuring balance and motor planning. The measure of gross motor skills consisted of four separate tasks (balancing, hopping, skipping, and walking backward). The psychomotor scale had alpha coefficients (reliability) for fine motor of 0.57 and for gross motor, 0.51 .

Children's social competence was assessed through both parent and teacher report. The Social Rating Scale (SRS) was administered to parents and teachers in the fall of the kindergarten year. The SRC asked parents and teachers to rate how often children exhibited certain kinds of behaviors related to particular social behaviors and skills. Children were rated on a four-point Likert scale with " 1 " being "student never exhibits this behavior," to "4" being "student exhibits this behavior most of the time." The Parent SRS had five scales: approaches to learning, self-control, social interaction, impulsive/overactive, and sad/lonely. As a measure of social competence the approaches to learning scale and the social interaction scale was used in this study. Approaches to learning included six items that rated how often a child demonstrates eagerness to learn, interest in a variety of things, creativity, persistence, concentration, and responsibility. Social interaction asked about children's interactions with other children as well as adults, and assessed the ease with which children joined in play, their ability to make and keep friends, and the degree to which they positively interact with peers. The split half reliability for the parent ratings of approaches to learning and social interaction scales are 0.68 and 0.70 , respectively.

The Teacher SRS also had five scales: approaches to learning, self-control, interpersonal 
skills, externalizing problem behaviors, and internalizing problem behavior. The Teacher SRS was self-administered in the fall of the kindergarten year. The approaches to learning and interpersonal skills scales were used for this study as a measure of children's social competence. In the Teacher SRS, the approaches to learning scale measured behaviors that affect the ease with which children can benefit from the learning environment and includes six items that measure children's attentiveness, task persistence, eagerness to learn, learning independence, flexibility, organization. The interpersonal skills scale rated children's skill in forming and maintaining friendships, getting along with individuals who are different than they, comforting or helping others, expressing feelings, ideas and opinions in a positive manner, and showing sensitivity to the feelings of others. The split half reliability for both the teacher ratings of approaches to learning and interpersonal skills was 0.89 .

\subsubsection{Children's Biological Development Factors}

Four biological development factors were used as independent variables in this study. These included gender, birth weight, health status, and kindergarten entry age. Each of these factors has been found it the literature to affect children's readiness for school.

In the ECLS-K, gender was a composite variable. The gender composite was derived using the gender indicated in the parent interview. If the gender designation was missing the Field Management System (FMS) was used. Throughout the data collection period, field supervisors entered data into the FMS about children, parents and teachers.

The birth weight status used for analyses was a categorical variable that indicated whether or not the child would be labeled as low birth weight. The categorical birth weight was calculated from the continuous birth weight variable collected by the ECLS-K from the parent interview and the birth records. Low birth weight is considered anything below 2500 grams (5.5 pounds). Using this criterion, children were divided into two categories. Those children that weight less than 5.5 pounds at birth were categorized as "low birth weight." Those children that weighed 5.5 pounds or more at birth were categorized as "normal birth weight."

The individual child's health status used for analyses was a categorical variable indicating that the child was in "excellent health," "good health," or "poor health." This variable was computed from a parent interview variable in which the primary caregiver rated a child's health status on a Likert scale in the following manner: $1=$ excellent, $2=$ very good, $3=$ good, 4 fair and $5=$ poor. These five categories were collapsed into three with a child being rated a " 1 " being categorized as "excellent health," a child rated a " 2 " or " 3 " being categorized as "good health," and a child rated a "4" or "5" being categorized as in "poor health."

The ECLS-K calculated the age at which each child was first assessed upon entering kindergarten. This was done by determining the number of days between the child's birth date and the date of the assessment. This value was then divided by 30 to calculate the child's kindergarten entry age in months. A categorical variable was then calculated from these data. Children who entered kindergarten below 65 months of age were categorized as "young" and children who entered kindergarten at 65 months or older were categorized as "old." This is consistent with the research on kindergarten entry age and its effect on academic achievement and social competence (Gullo \& Burton, 1992; Uphoff\& Gilmore, 1985). 


\subsection{Analysis Plan}

In order to determine if there were significant differences among the biological variables with respect to factors related to kindergarten readiness, multivariate analyses of variance (MANOVA) were performed with children's biological factors as independent variables and clusters of readiness factors as dependent variables. The readiness factors were clustered into four groups that included cognitive factors (reading, math, general knowledge), psychomotor factors (fine and gross motor performance), parent rating of social competence (approaches to learning and social interaction), and teacher rating of social competence (approaches to learning and interpersonal). Prior to running the MANOVAs, correlations among the clusters of dependent variables were run to determine if they were related and consequently whether it was appropriate to use MANOVA. All correlations were moderate to higher and were significant $(\mathrm{p}<.001)$.

Prior to analysis, the data were weighted in accordance with the weighting criterion establish for the ECLS-K data. Base year, cross sectional weighting was applied to the data.

\section{Results}

The research question for this investigation was "what are the effects of children's biological characteristics (birth weight, gender, health rating, and kindergarten entry age) on school readiness variables clustered into factors related to cognitive development, psychomotor development and social competence?" Descriptive statistics were computed for each of the independent and dependent variables. In order to answer the research question, MANOVAs were performed on each cluster of readiness factors with children's biological development factors used as independent variables. Weighted means and standard deviations are included in the table.

For the cognitive readiness factors, results of the MANOVAs revealed significant multivariate tests for three main effects (birth weight risk, health status, and kindergarten entry age) and one interaction (birth weight risk $\mathrm{X}$ health status). Examination of the univariate results and means for kindergarten entry age revealed that children who entered kindergarten at an older age, scored significantly higher on reading, math, and general knowledge tests of achievement than children who entered kindergarten at an older age. Since there was a significant birth weight risk $\mathrm{X}$ health status interaction, main effects for birth weight risk and health status were not examined. Means and standard deviations for the cognitive factors can be found in Table 1. Significant multivariate and univariate results for the cognitive factors can be found in Table 2 . 
Table 1. Descriptive statistics for cognitive factors (Means and Standard Deviations)

$\begin{array}{lll}\text { Reading } & \text { Math } & \text { General } \\ & \text { Knowledge }\end{array}$

\section{Gender}

\begin{tabular}{llll} 
Boy & $30.79(8.38)$ & $22.36(7.20)$ & $18.64(6.38)$ \\
Girl & $31.42(6.48)$ & $22.22(6.40)$ & $18.43(6.18)$ \\
\hline Birth Weight & & $20.86(6.29)$ & $17.34(6.28)$ \\
Low & $30.37(6.94)$ & $22.45(7.22)$ & $18.67(6.26)$ \\
Normal & $31.19(6.40)$ & & \\
\hline Health Status & & $20.10(6.57)$ & $16.44(5.71)$ \\
Poor & $29.10(5.48)$ & $21.30(6.38)$ & $17.09(5.84)$ \\
Good & $30.17(6.22)$ & $22.53(6.85)$ & $18.84(6.31)$ \\
Excellent & $31.32(6.95)$ & $20.62(5.85)$ & $16.92(5.79)$ \\
\hline Kindergarten Age & & $23.65(7.25)$ & $19.78(6.34)$ \\
Young & $29.83(5.55)$ & & \\
Old & $32.09(7.60)$ & &
\end{tabular}

Table 2. MANOVA and Univariate F Values for the effects of biological factors on children's cognitive readiness

\begin{tabular}{|c|c|c|c|c|c|}
\hline \multirow[b]{2}{*}{ Variable } & \multicolumn{2}{|c|}{$\begin{array}{l}\text { MANOVA on } \\
\text { Cognitive Factors }\end{array}$} & \multicolumn{3}{|c|}{$\begin{array}{l}\text { Univariate Tests } \\
\text { on Cognitive Factors }\end{array}$} \\
\hline & dfs & $\mathrm{F}$ & Reading F & Math F & $\begin{array}{l}\text { General } \\
\text { Knowledge } \mathrm{F}\end{array}$ \\
\hline Gender & 3,4200 & 0.73 (NS) & $1.70(\mathrm{NS})$ & $0.19(\mathrm{NS})$ & $0.03(\mathrm{NS})$ \\
\hline BW Risk & 3,4200 & $4.65^{*}$ & $2.82(\mathrm{NS})$ & $11.37 * *$ & $8.04 *$ \\
\hline Health Status & 3,4200 & $3.70 * *$ & $5.68 *$ & $8.35 * *$ & $8.60 * *$ \\
\hline K Age & 3,4200 & $13.49 * *$ & $15.88 * *$ & $31.77 * *$ & $30.43 * *$ \\
\hline $\begin{array}{l}\text { BW Risk X Health } \\
\text { Status }\end{array}$ & 6,8400 & $2.85^{*}$ & $1.53(\mathrm{NS})$ & $0.73(\mathrm{NS})$ & $7.11 * *$ \\
\hline
\end{tabular}

With regard to the significant birth weight risk $\mathrm{X}$ health status interaction, univariate analyses revealed significant findings for general knowledge only. Follow-up analyses showed that within the at-risk birth weight group there was a significant difference in general knowledge between the children who had a "poor health rating" and those who had either a "good health 
rating" or an "excellent health rating." Children who had a "poor health rating" scored lower than either of the other two groups. There was no difference between those children with either a "good" or "excellent" health rating. Within the non-at risk birth weight group, the pattern was different. There was a significant difference in general knowledge score between the children who had an "excellent health rating" and those who had a "poor" or "good health rating," with those who had an "excellent health rating" having higher scores. There was no difference between children in the "poor" or "good health rating" groups.

MANOVAs for psychomotor factors revealed significant main effects for gender, birth weight risk, health status, and kindergarten entry age. No significant interactions were found. Means and standard deviations for the psychomotor factors can be found in Table 3. Significant multivariate and univariate results for psychomotor factors can be found in Table 4.Examination of the univariate tests and means for gender revealed that girls scored higher than boys on measures of fine and gross motor ability. The univariate tests and means for birth weight showed that children who were born with low birth weight scored significantly lower than children born at normal birth weights for fine motor but not for gross motor development at the beginning of kindergarten. Univariate tests for health status showed that there were significant differences for both fine and gross motor development. Post hoc analyses using Scheffe indicated that for fine motor skills, those children who had an "excellent health rating" scored significantly higher than those having either a "good" (p. $<.001$ ) or "poor health rating" (p. $<.001)$. There were no differences between those rated as "good" or "poor." Scheffe analyses also revealed that for gross motor skills children whose health status that was rated as either "good" or "excellent" had significantly higher gross motor scores than children who were rated as "poor," (p. $<05$ and p. $<.001$, respectively).

Table 3. Descriptive Statistics for Psychomotor Factors (Means and Standard Deviations)

\begin{tabular}{lll}
\hline & Fine Motor & Gross Motor \\
\hline Gender & & \\
Boy & $5.10(2.17)$ & $5.98(2.02)$ \\
Girl & $5.37(2.11)$ & $6.35(1.84)$ \\
\hline Birth Weight & & \\
Low & $4.80(2.22)$ & $6.13(2.02)$ \\
Normal & $5.28(2.13)$ & $6.17(1.93)$ \\
\hline Health Status & & $5.70(2.25)$ \\
Poor & $4.70(2.23)$ & $6.10(1.97)$ \\
Good & $5.01(2.17)$ & $6.22(1.90)$ \\
Excellent & $5.30(2.13)$ & \\
\hline Kindergarten Age & & $5.92(2.01)$ \\
Young & $4.73(2.13)$ & $6.41(1.83)$ \\
Old & $5.68(2.06)$ &
\end{tabular}


Table 4. MANOVA and Univariate $\mathrm{F}$ Values for the Effects of Biological Factors on Children's Psychomotor Readiness

\begin{tabular}{lllll}
\hline & \multicolumn{2}{l}{$\begin{array}{l}\text { MANOVA on } \\
\text { Psychomotor Factors }\end{array}$} & \multicolumn{2}{l}{$\begin{array}{l}\text { Univariate Tests } \\
\text { on Psychomotor Factors }\end{array}$} \\
\hline Variable & dfs & F & Fine Motor F & Gross Motor F \\
Gender & 2,4771 & $5.86^{*}$ & $4.76^{*}$ & $9.38^{*}$ \\
BWRisk & 2,4771 & $5.35^{*}$ & $9.74^{*}$ & $2.76(\mathrm{NS})$ \\
Health Status & 4,9542 & $5.50^{* *}$ & $6.41^{*}$ & $5.99^{*}$ \\
K Age & 2,4771 & $17.96^{* *}$ & $31.74^{* *}$ & $10.68^{* *}$ \\
\hline
\end{tabular}

$* * p<.001, * p<.01$.

MANOVAs for parents' rating of social competence factors (approaches to learning and social interaction) revealed significant main effects for gender and health status. No other main effects or interactions were significant. Means and standard deviations for the parents' ratings of social competence can be found in Table 5. Significant multivariate and univariate results for parents' ratings of children's social competence can be found in Table 6.Examination of the univariate tests for gender revealed that girls scored significantly higher than boys on approaches to learning, but there was no difference between boys' and girls' scores on parents' rating of social interaction. The univariate tests for health status revealed significant differences for both approaches to learning and social interaction. Post hoc analyses using the Scheffe method revealed that children who health status was rated as "excellent" scored significantly higher on parents' ratings of approaches to learning than children who were rated as either "good" (p. < .001) or "poor" (p. < .001). Children who were rated as "good" scored significantly higher than children who were rated as "poor" (p. $<.01)$. With regard to parents' ratings of social interaction, post hoc analyses revealed that children who health status was rated as "excellent" scored significantly higher than children who were rated as either "good" (p. <.001) or "poor" (p. <.001). Children who were rated as "good" scored significantly higher than children who were rated as "poor" (p. <.01). 
Table 5. Descriptive Statistics for Parent Ratings of Social Competence (Means and Standard Deviations)

\begin{tabular}{lll}
\hline & Approaches to Learning & Social Interaction \\
\hline Gender & & \\
Boy & $2.96(0.50)$ & $3.18(0.60)$ \\
Girl & $3.07(0.50)$ & $3.24(0.59)$ \\
\hline Birth Weight & & \\
Low & $3.03(0.51)$ & $3.19(0.61)$ \\
Normal & $3.01(0.50)$ & $3.21(0.59)$ \\
\hline Health Status & & \\
Poor & $2.81(0.53)$ & $2.97(0.67)$ \\
Good & $2.89(0.49)$ & $3.07(0.61)$ \\
Excellent & $3.04(0.50)$ & $3.25(0.58)$ \\
\hline Kindergarten Age & & $3.18(0.60)$ \\
Young & $2.99(0.51)$ & $3.22(0.60)$ \\
Old & $3.01(0.51)$ & \\
\hline
\end{tabular}

Table 6. MANOVA and Univariate F Values for the Effects of Biological Factors on Parents' Ratings of Social Competence

\begin{tabular}{lllll}
\hline \multicolumn{4}{c}{$\begin{array}{l}\text { MANOVA on } \\
\text { Psychomotor Factors }\end{array}$} & $\begin{array}{l}\text { Univariate Tests } \\
\text { on Psychomotor Factors }\end{array}$ \\
\hline Variable & dfs & F & Approaches to Learning & Social Interaction \\
Gender & 2,4958 & $3.78^{*}$ & $7.46^{*}$ & $0.91(\mathrm{NS})$ \\
BW Risk & 2,4958 & $0.61(\mathrm{NS})$ & & $22.15^{* *}$ \\
Health Status & 4,9918 & $16.19^{* *}$ & $24.78^{* *}$ & \\
K Age & 2,4958 & $0.47(\mathrm{NS})$ & & \\
\hline$* * p<.001, * p<.01$. & & &
\end{tabular}

MANOVAs for teachers' rating of social competence factors (approaches to learning and interpersonal) revealed significant main effects for gender, health status, and kindergarten entry age. In addition, there was a significant birth weight risk $\mathrm{X}$ health status interaction. No other main effects or interactions were significant. Means and standard deviations for the teachers' ratings of social competence can be found in Table 7. Significant multivariate and univariate results for teacher's ratings of children's social competence can be found in Table 8.Examination of the univariate tests for gender revealed that girls scored significantly higher 
than boys on teachers' ratings of approaches to learning and interpersonal. The univariate tests for kindergarten entry age revealed significant differences for both approaches to learning and social interaction. In both instances, children who entered kindergarten older were rated higher than children who entered kindergarten younger. Due to the significant birth weight $\mathrm{X}$ health status interaction, the main effect for health status was not examined. The univariate tests for the interaction revealed no significant differences for either the teachers' ratings of approaches to learning or interpersonal.

Table 7. Descriptive Statistics for Teacher Ratings of Social Competence (Means and Standard Deviations)

\begin{tabular}{ccc}
\hline & Approaches to Learning & Social Interaction \\
\hline Gender & $2.73(0.68)$ & $2.76(0.62)$ \\
Boy & $2.95(0.67)$ & $2.95(0.62)$ \\
Girl & & \\
\hline Birth Weight & $2.73(0.68)$ & $2.82(0.63)$ \\
Low & $2.86(0.68)$ & $2.86(0.63)$ \\
Normal & & \\
Health Status & $2.65(0.73)$ & $2.74(0.64)$ \\
Poor & $2.76(0.69)$ & $2.76(0.63)$ \\
Good & $2.87(0.68)$ & $2.88(0.62)$ \\
Excellent & & $2.82(0.62)$ \\
Kindergarten Age & $2.75(0.67)$ & $2.88(0.63)$ \\
Young & $2.92(0.68)$ & \\
Old & &
\end{tabular}

Table 8. MANOVA and Univariate F Values for the Effects of Biological Factors on Teachers' Ratings of Social Competence

\begin{tabular}{lllll}
\hline & \multicolumn{2}{c}{$\begin{array}{c}\text { MANOVA on } \\
\text { Psychomotor Factors }\end{array}$} & \multicolumn{2}{c}{$\begin{array}{c}\text { Univariate Tests } \\
\text { on Psychomotor Factors }\end{array}$} \\
\hline Variable & $\mathrm{dfs}$ & $\mathrm{F}$ & Approaches to Learning & Interpersonal \\
Gender & 2,4619 & $10.19^{* *}$ & $18.32^{* *}$ & $16.21^{* *}$ \\
BW Risk & 2,4619 & $2.72(\mathrm{NS})$ & & \\
Health Status & 4,9238 & $7.26^{* *}$ & $6.30^{*}$ & $11.03^{* *}$ \\
K Age & 2,4619 & $8.78^{* *}$ & $14.68^{* *}$ & 2.18 (NS) \\
BW Risk X Health & 2,4619 & $3.66^{*}$ & $2.49(\mathrm{NS})$ & 0.80 (NS) \\
Status & & & & \\
\hline$* * p<.001 * p<.01$ & & & &
\end{tabular}




\section{Discussion}

The present study was designed to investigate the relative effects of children's biological characteristics on factors related to kindergarten readiness for children who reside in homes of economic poverty. While many previous investigations have examined SES differences in school readiness, few have studied the differential effects of factors affecting school readiness within a low-SES group of children. According to Conger, Conger, and Martin (2010), "An apriori assumption of most research on SES ... is that social position influences families across time, and that socioeconomic disadvantage has negative consequences for adults and children" (p. 688). By examining SES differences in school readiness, children in these studies are grouped according to their social and economic status, resulting in a paucity of information regarding within group differences. The kindergarten readiness factors that were studied in this investigation were clustered around four areas. These areas included cognitive or achievement, psychomotor development, parents' ratings of social competence, and teachers' ratings of social competence.

In previous investigations examining factors affecting kindergarten readiness, gender has been found to be a significant variablerelated to children's levels of academic performance. Studies have shown that girls outperform boys on measures of reading, math, and general knowledge (Gullo \& Burton, 1992; Isaacs, 2012, Janus \& Duku, 2007). In the present study, gender was not a significant determinantamongthe cognitive readiness factors measured related to achievement in reading, math, or general knowledge. This finding is consistent with the findings of another study that examined school readiness factors among Head Start urban children (Zhai, Brooks-Gunn, \& Waldfogel, 2011). In this study the researchers found that neither gender nor race/ethnicity were moderating factors that determined children's school readiness. The lack of findings regarding gender may partly be due to low-SES families not differentially treating boys and girls when it comes to early schooling practices (Winsler, et. al., 2012). Parental practices related to early schooling and that also acknowledged boys' and girls' differential developmental needs were common among middle- and upper-SES families, but not among low-SES families. This was particularly true when it came to schooling issues related to cognitive development and academic achievement.

Gender was significant, however, among the readiness factors related to psychomotor development, as well as in parents' and teachers' ratings of social competence. In each instance, girls scored higher than boys. The finding that girls outperformed boys on measures of fine and gross motor development was probably due to differences in maturational rates between and girls at this age. Additionally, girls were rated higher than boys by both parents and teachers on measures of social competence, particular on the measure of approaches to learning. This finding is consistent with other studies that found that boys are often "viewed" as less mature and less socially ready for kindergarten than are girls (Ede, 2004; Winsler et al., 2012). The interesting finding here is that the differences in gender in this study are consistent with that of other studies only for variables related to biological maturation and parents' and teachers' perceptions of children. The findings related to classroom performance (achievement) are not consistent with other studies' findings, however. This may imply that social class has a differential effect on children's academic performance than it does on other types of school readiness factors. Future research should be done to elucidate how the 
differences in socialization that children of different social classes experience may affect these aforementioned factors differently.

In this study, a child's birth weight was only significant on factors related to academic achievement or child development. Children who were not categorized as low birth weight scored higher on measures of academic achievement and psychomotor development as compared to children who were categorized as low birth weight. Birth weight did not have an effect on parents' or teachers' ratings of social competence. This was an unexpected finding in that research has shown that children who were low birth weight, often had higher incidence of behavioral difficulties and displayed inattentive behaviors when starting school (Anderson \& Doyle, 2003; Bhutta, 2002; Nonkin et al., 2001). While birth weight is not a biological factor that is mutable, studies indicate that children who come from low-SES homes are more likely to be of low birth weight than children born to higher SES families (Isaacs, 2012). This is most likely due to factors related to nutrition, health care resources, and general prenatal care. The implications of the findings from this study are that among low-SES children, those whose birth weight was in the normal range were advantaged academically, cognitively, and in their psychomotor development. Therefore, more efforts should be placed on prenatal and preventative interventions among low-SES families to reduce the risk of low birth weight.

Children's health status had a significant effect on measures of academic achievement, psychomotor development, and on parents' and teachers' ratings of social competence. Generally speaking, children who were rated as having excellent health scored consistently higher than children than children who were rated as having poor health. While these findings are consistent with the findings of other studies (Janus \& Daku, 2007; Naude \& Pretorius, 2003), what's significant here is that among low-SES children, there are differences in academic performance, child development, and ratings of social competence depending on the status of their health. In general, it has been found that there is a documented relationship between health status and SES for both children and adults (Bradley \& Corwyn, 2002). Children who come from low-SES homes are more likely to experience health issues starting at birth. In addition, when low SES children experience health issues, the consequence of these issues are often times more severe as compared to their higher SES counterparts. Evidence from this study's findings suggests that low SES children whose health status is excellent are developmentally and academically advantaged as compared to low SES children whose health status is poor. Therefore, particular care should be taken to insure that low SES families receive prenatal and postnatal health care services that will decrease the likelihood that children in these families will experience chronic poor health. The findings from this study indicate that health status can be seen as a differentiating factor affecting all aspects of school readiness among low-SES children.

In this study, children's chronological age at kindergarten entry had a significant effect on all readiness variables except for parents' ratings of social competence. In each instance, children who were older when they entered kindergarten scored higher on measures of academic achievement and psychomotor development as well as on teachers' ratings of social competence. These findings are consistent with other studies' findings (Crosser, 1991; Gullo \& Burton, 1992; Janus et al., 2007; NICHD, 2007). In studying the effect of age on 
kindergarten readiness, Zill and West (2001) found that teachers rated children who were older in their classes as exhibiting more of a positive approach towards school and were more persistent in completing tasks than were younger children. Both of these social characteristics represent elements of approaches to learning and interpersonal skills which were the social competence variables examined in this study. One of the reasons why there may not have been an age effect on parents' ratings was that parents rated their children without any basis for comparison. Teachers, on the other hand, rated children in the context of the classroom and were able to see how each child performed comparatively to the other children in the class (e.g., older vs. younger). While controversial, an implication of this finding may be that children who come from low-SES families delay entry into kindergarten if they are young for their class. In this study, older children did better than younger children on all but one measure of school readiness, both boys and girls. While delaying school entry is more prevalent among families of higher SES, particularly for boys (Winsler et al., 2012), it is quite rare among low-income working families. Perhaps, therefore, delaying school entry for younger boys and girls in low SES families would be beneficial for them developmentally, academically, and socially. One has to keep in mind and weigh the fact, however, that delaying school entry for low-income working families might be a hardship due to an additional year of expensive childcare arrangements or preschool.

\section{Implications and Future Directions}

The most significant implications of this investigation have to do with those findings that demonstrate that children who come from low-SES backgrounds are not a homogeneous group with regard to kindergarten readiness. There are differences among them that will contribute to or take away from their being prepared for school. While certain factors in this study seemed to increase measured kindergarten readiness variables, it is not known whether those children who scored higher on these variables would be considered as ready for kindergarten when compared to children from higher SES groups. More research needs to be done that focuses on predicting how clusters of variables will predict school readiness among and between groups of children from varying SES groups.

While school or kindergarten readiness suggests that children have certain developmental or academic characteristics and skills, it would also be important to elucidate how having these characteristics and skills will affect future academic and social competence. As stated in the introduction, little research has been done to examine the differences that exist among children who come from low-SES home. Most of the previous research compares low-SES children to children of other social class backgrounds. It is evident that there may be factors in these children's lives that are causing the differences among them that are seen in the results of this study. Future research should be done to determine why these differences exist and what factors in children's lives are causing them.

Another significant implication of this investigation has to do with the findings demonstrating that among low-SES children there are different patterns of academic achievement, development, and social competence as compared to children in other SES groups from other studies. This may be due to the differential impact that factors in the child's life has on these elements. It is evident from the findings in this investigation that the readiness factors examined appear to affect low-SES children differently than they do children from other SES 
groups. The impact of these factors on school readiness is different than what has been found in previous research and therefore different types of implications for teaching and caring for children should be drawn from these findings. Knowing this information will better inform practice, teacher training, and future research.

\section{References}

Anderson, P., \& Doyle, L. (2003). Neurobehavioral outcomes of school-age children born extremely low birth weight or very preterm in the 1990s. Journal of the American Medical Association, 289(24), 3264-3272. http://dx.doi.org/10.1001/jama.289.24.3264

Ayoub, C., O'Connor, E., Rappolt-Schlictmann, G., Vallotton, C., Raikes, H., \& Chazan-Cohen, R. (2009). Cognitive skill performance among young children living in poverty: Risk, change, and the promotive effects of early Head Start. Early Childhood Research Quarterly, 24(3), 289-305. http://dx.doi.org/10.1016/j.ecresq.2009.04.001

Barlow, H. J., \& Ellard, D. R. (2006). The psychosocial well-being of children with chronic disease, their parents and siblings: An overview of the research evidence base. Child: Care, Health and Development, 32, 19-31. http://dx.doi.org/10.1111/j.1365-2214.2006.00591.x

Bhutta, A. T. (2002). Cognitive and behavioral outcomes of school-aged children whowere born preterm: A meta-analysis. Journal of the American Medical Association, 288(6), 228-237. http://dx.doi.org/10.1001/jama.288.6.728

Bradley, R. H., \& Corwyn, R. F. (2002). Socioeconomic status and child development. Annual Review of Psychology, 371-399. http://dx.doi.org/10.1146/annurev.psych.53.100901.135233

Card, D. (1999). The causal effect of education on earnings. In O. Ashenfelter \& D. Card (Eds.). Handbook of labor economics (Vol. 3, pp. 1801-1863). Amsterdam, the Netherlands, Elsevier.

Carlton, M. P., \& Winsler, A. (1999). School readiness: The need for a paradigm shift. School Psychology Review, 28, 338-352.

Classens, A., Duncan, G., \& Engel, M. (2009). Kindergarten skills and fifth-grade achievement: Evidence from the ECLS-K. Economics of Education Review, 28, 415-427. http://dx.doi.org/10.1016/j.econedurev.2008.09.003

Conger, R. D., Conger, K. J., \& Martin, M. J. (2010). Socioeconomic status, family processes, and individual development. Journal of Marriage and Family, 72(3), 685-704. http://dx.doi.org/10.1111/j.1741-3737.2010.00725.x

Cross, A. F., \& Conn-Powers, M. (2011). A working paper: New information on school readiness. Retrieved from http://www.iidc.indiana.edu/styles/iidc/defi es/ECC/New\%20Info\%20School\%20Readiness.pdf

Crosser, S. L. (1991). Summer birth date children: Kindergarten entrance age and academic achievement. The Journal of Educational research, 84(3), 140-146. 
Cryan, J., Sheehan, R., Wiechel, J., \& Bandy-Hedden, I. G. (1992). Success outcomes of full-day kindergarten: More positive behavior and increased achievement in the years after. Early Childhood Research Quarterly, 187-203. http://dx.doi.org/10.1016/0885-2006(92)90004-I

Downey, D., von Hippel, P., \& Beckett, A. (2004). Are schools the great equalizer? Cognitive inequality during the summer months and the school year. American Sociological Review, 69, 613-635. http://dx.doi.org/10.1177/000312240406900501

Duncan, G., Claessens, A., Huston, A., Pagani, L., Engel, M., Dowsett, C., ... Japel, C. (2007). School readiness and later achievement. Developmental Psychology, 43(6), 1428-1446. http://dx.doi.org/10.1037/0012-1649.43.6.1428

Duncan, G., Morris, P. A., \& Rodrigues, C. (2011). Does money really matter? Estimating impacts of family income on children's achievement with data from random-assignment $\begin{array}{lll}\text { experiments. } \quad \text { Developmental } & \text { Psychology, } & \text { 47(5), }\end{array}$ http://dx.doi.org/10.1037/a0023875

Ede, A. (2004). Is my child really too young for kindergarten? Childhood Education, 80(4), 207-208. http://dx.doi.org/10.1080/00094056.2004.10522235

Engle, P. L., \& Black, M. M. (2008). The effect of poverty on child development and educational outcomes. Annals of the New York Academy of Sciences, 1136, 243-256. http://dx.doi.org/10.1196/annals.1425.023

Entwisle, D., Alexander, K., \& Olsen, L. (2005). First grade and educational attainment by age 22: A new story. American Journal of Sociology, 110, 1458-1502. http://dx.doi.org/10.1086/428444

Fedor, M., Bender, S., \& Carlson, J. (2010). Examining risk and protective factors in Head Start populations located in high- and low-violence communities. Infants and Young Children, 23(3), 209-217. http://dx.doi.org/10.1097/IYC.0b013e3181e1a211

Gullo, D. F., \& Burton, C. (1992). Age of entry, preschool experience, and sex as antecedents of academic readiness in kindergarten. Early Childhood Research Quarterly, 7, 175-186. http://dx.doi.org/10.1016/0885-2006(92)90003-H

Gullo, D. F., \& Hughes, K. (2011). Reclaiming kindergarten - Part I: Questions about practice. Early Childhood Education Journal, 38, 323-328. http://dx.doi.org/10.1007/s10643-010-0430-0

Hair, E., Halle, T., Terry-Humen, E., Lavelle, B., \& Calkins, J. (2006). Children's school readiness in the ECLS-K: Predictions to academic, health, and social outcomes in first grade. Early Childhood Research Quarterly, 21, 431-454. http://dx.doi.org/10.1016/j.ecresq.2006.09.005

Heckman, J. J. (2006). Skill formation and the economics of investing in disadvantaged children. Science, 312, 446-474. http://dx.doi.org/10.1126/science.1128898 
Hughes, K., \& Gullo, D. F. (2010). Joyful learning and assessment in kindergarten.Young Children, 65(3), 57-59.

Isaacs, J. (2012). Starting school at a disadvantage: The school readiness of poor children. Washington, DC: The Brookings Institution.

Isaacs, J., Sawhill, I., \& Haskins, R. (2008). Getting ahead or losing ground: Economic mobility in America. Washington, DC: The Brookings Institution.

Janus, M., Brinkman, S., Duku, E., Hertzman, C., Santos, R., \& Sayers, M. (2007). The early development instrument: A population-based measure for communities. A handbook on development, properties, and use. Hamilton, Ontario, Canada: Oxford Centre for Child Studies. http://dx.doi.org/10.1080/10409280701610796a

Janus, M., \& Duku, E. (2007). The school entry gap: Socioeconomic, family, and health factors associated with children's school readiness to learn. Early Education and Development, 18(3), 375-403. http://dx.doi.org/10.1080/10409280701610796a

Kagan, S. L., Moore, E., \& Bredekamp, S. (1995). Reconsidering children's early development and learning: Toward common views and vocabulary. Washington, DC: National Education Goals Panel Goal 1 Technical Planning Group.

Lee, V., \& Burkam, D. (2002). Inequality at the starting gate: Social background differences in achievement as children begin school. Washington, DC: Economic Policy Institute.

Li-Grining, C. P., Votruba-Drzal, E., Maldonado-Carreño, C., \& Haas, K. (2010). Children's early approaches to learning and academic trajectories through fifth grade. Developmental Psychology, 46(5), 1062-1077. http://dx.doi.org/10.1037/a0020066

May, D., \& Kundert, D. (1997). School readiness practices and children at risk: Examining the issues. Psychology in the Schools, 34, 73-84. http://dx.doi.org/10.1002/(SICI)1520-6807(199704)34:2\%3C73::AID-PITS1\%3E3.0.CO;2-T

Meisels, S. J. (1999). Assessing readiness. In R. C. Pianta (Ed.), The transition to kindergarten (pp. 39-66). Baltimore, MD: Paul H. Brookes Publishing Co.

National Center for Children in Poverty \& Abt Associates. (2008). Proceedings from a working meeting on recent school readiness research: Guiding the synthesis of early childhood research. Washington, DC: Retrieved from http://aspe.hhs.gov/hsp/10/SchoolReeadiness/index.pdf

National Center for Educational Statistics. (2000). Early Childhood Longitudinal Study: ECLS-K Base Year Data Files and Electronic Codebook. Washington, DC: U.S. Department of Education.

National Center for Educational Statistics. (2001). User's manual for the ECLS-K base year public-use data files and electronic code book. Washington, DC: U.S. Department of Education.

Naude, H. \& Pretorius, E. (2003). Investigating the effects of asthma medication on the 
cognitive and psychosocial functioning of primary school children with asthma. Early Child Development and Care, 173, 699-709. http://dx.doi.org/10.1080/0300443032000178645

NICHD. (2007). Age of entry to kindergarten and children's academic achievement and socioemotional development.Early Education and Development, 18(2), 337-368. http://dx.doi.org/10.1080/10409280701283460

Nonkin, A., Scott, K.; \& Mason, C. (2002). Birth weight and school-age disabilities: A population-based study. American Journal of Epidemiology, 154(10), 895-901.

Perroncel, C. B. (2000). Getting Kids Ready for School in Rural America. Retrieved from http://www.eric.ed.gov/PDFS/ED445849.pdf

Pianta, R., \& Cox, M. (1999). Transition to kindergarten. Baltimore: Paul H. Brooks Publishing Co.

Ready, D. (2010). Socioeconomic disadvantage, school attendance, and early cognitive development: The differential effects of school exposure. Sociology of education, 83(1), 271-286. http://dx.doi.org/10.1177/0038040710383520

Reardon, S. (2003). Sources of educational inequality: The growth of racial/ethnic and socioeconomic test score gaps in kindergarten and first grade. University Park, PA: Population Research Institute, Pennsylvania State University.

Romano, E., Babchishin, L., Pagani, L. S., \& Kohen, D. (2010). School readiness and later achievement: Replication and extension using a nationwide Canadian survey. Developmental Psychology, 46(5), 995-1007. http://dx.doi.org/10.1037/a0018880

Spitzer, S., Cupp, R., \& Parke, R. D. (1995). School entrance age, social acceptance, and self-perceptions in kindergarten and $1^{\text {st }}$ grade. Early Childhood Research Quarterly, 10, 433-450. http://dx.doi.org/10.1016/0885-2006(95)90015-2

Stipek, D. (2002). At what age should children enter kindergarten? A question for policy makers and parents. Society for Research in Child Development Social Policy Report, 16, 1-16.

Uphoff, J. K., \& Gilmore, J. (1985). Pupil age at school entrance - How many are ready for success? Educational Leadership, 43, 86-90.

Winship, S., Sawhill, I., \& Gold, A. (2011, November). Pathways to the middle class. Paper presented at the Social Genome Project Conference at Brookings, Washington, DC.

Winsler, A., Hutchinsion, A., DeFeyter, J. J., Bleiker, C., Manfra, L., Hartman, S. C., \& Levitt, J. (2012). Child, family, and childcare predictors of delayed school entry and kindergarten retention among linguistically and ethnically diverse children. Developmental Psychology, 48(5), 1299-1314. http://dx.doi.org/10.1037/a0026985

Zhai, F., Brooks-Gunn, J., \& Waldfogel, J. (2011). Head start and urban children's school readiness: A birth cohort study in 18 cities. Developmental Psychology, 47(1), 134-152. http://dx.doi.org/10.1037/a0020784 


\section{Macrothink}

Journal of Social Science Studies

ISSN 2329-9150 2015, Vol. 2, No. 1

Zigler, E., Gilliam, W., \& Jones, S. (2006). A vision for universal preschool education. New York: Cambridge University Press. http://dx.doi.org/10.1017/CBO9781139167284

Zill, N., \& West, J. (2004). Entering kindergarten: A portrait of American children when they begin school: Findings from the condition of education 2000. Washington, DC: U.S. Department of Education, National Center for Educational Statistics.

\section{Copyright Disclaimer}

Copyright reserved by the author(s).

This article is an open-access article distributed under the terms and conditions of the Creative Commons Attribution license (http://creativecommons.org/licenses/by/3.0/). 